\title{
Recombinant expression, purification and characterization of Bombyx mori (Lepidoptera: Bombycidae) pyridoxal kinase
}

\author{
Shuo-Hao HUANG ${ }^{1,2}$, WAng MA ${ }^{1}$, Ping-Ping ZHANG ${ }^{3}$, JiAn-Yun ZHANG ${ }^{3}$, Yan-Feng XIE ${ }^{1}$ \\ and LONG-QUAN HUANG ${ }^{1 *}$ \\ ${ }^{1}$ Key Laboratory of Tea Biochemistry \& Biotechnology of Ministry of Education and Ministry of Agriculture, \\ Anhui Agricultural University, Hefei 230036, People's Republic of China \\ ${ }^{2}$ Graduate School of Systems Life Sciences, Kyushu University, 744 Motooka, Nishi-ku, Fukuoka 819-0395, Japan \\ ${ }^{3}$ College of Life Science, Anhui Agricultural University, Hefei 230036, People's Republic of China
}

Key words. Bombyx mori, pyridoxal kinase, recombinant expression, purification, characterization

\begin{abstract}
Pyridoxal kinase (PLK; EC 2.7.1.35) is a key enzyme in the metabolism of vitamin $\mathrm{B}_{6}\left(\mathrm{VB}_{6}\right)$ in Bombyx mori. A fusion expressional vector pET-22b-BPLK-His was constructed using a sub-cloning technique, the recombinant $B$. mori PLK was then expressed in Escherichia coli, purified and characterized. Bioinformatics were used to deduce the protein structure and genomic organization of this enzyme. Using Ni Sepharose affinity column chromatography, the recombinant protein was purified to very high degree (approximately 90\%). The recombinant PLK exhibits a high specific enzymatic activity ( $1800 \mathrm{nmol} / \mathrm{min} / \mathrm{mg}$ of protein). The maximum catalytic activity of this enzyme was recorded over a narrow $\mathrm{pH}$ range (5.5-6.0) and $\mathrm{Zn}^{2+}$ is the most effective cation for catalysis under saturating substrate concentrations. When only triethanolamine is present as the cation, $\mathrm{K}^{+}$is an activator of PLK. A double reciprocal plot of initial velocity suggests that the enzyme catalyses the reaction by means of a sequential catalytic mechanism. Under optimal conditions, the Km value for the substrates of ATP and pyridoxal are $57.9 \pm 5.1$ and $44.1 \pm 3.9 \mu \mathrm{M}$. B. mori's genome contains a single copy of the $P L K$ gene, which is $7.73 \mathrm{~kb}$ long and contains five exons and four introns, and is located on the eighth chromosome. The PLK may be a dimer with two identical subunits under native conditions, and it is hypothesized that each monomer contains eight $\alpha$-helices ( $\alpha 1-8)$, nine $\beta$-strands ( $\beta 1-9)$ and two segments of $3_{10}$ helices.
\end{abstract}

\section{INTRODUCTION}

Vitamin $\mathrm{B}_{6}\left(\mathrm{VB}_{6}\right)$ exists in various forms, pyridoxal $(\mathrm{PL})$, pyridoxine $(\mathrm{PN})$, pyridoxamine $(\mathrm{PM})$ and their phosphorylated derivatives: Pyridoxal 5'-phosphate (PLP), pyridoxine 5'-phosphate (PNP) and pyridoxamine 5'-phosphate (PMP). PLP is the active form of $\mathrm{VB}_{6}$ and acts as an essential, ubiquitous coenzyme in many aspects of amino acid and cellular metabolism. The de novo biosynthesis of $\mathrm{VB}_{6}$ takes place in microorganisms and plants, but animals have lost this ability and it is essential they include it in their diet for the biosynthesis of PLP via a salvage pathway. In the salvage pathway, pyridoxal kinase (PLK) (EC 2.7.1.35) catalyzes the ATP-dependent phosphorylation of PL, PM and PN to form PLP, PMP and PNP, respectively. PNP and PMP are oxidized to form PLP by pyridoxine 5'-phosphate oxidase (PNPO; EC 1.4.3.5).

PLKs from bacteria and mammals have been purified and characterized (White \& Dempsey, 1970; Kwok \& Churchich, 1979; Kerry et al., 1986; Kerry \& Kwok, 1986; Kwok et al., 1987; Sakurai et al., 1993). The gene encoding PLK has been isolated from mammals (Hanna et al., 1997; Gao et al., 1998; Maras et al., 1999), microorganisms (Yang et al., 1996, 1998; Scott \& Phillps, 1997) and plants (Lum et al., 2002; Wang et al., 2004). Several mammalian PLKs have been successfully expressed in Escherichia coli and the expressed recombinant proteins exhibit the same biochemical characteristics as those of the native protein purified from various mammalian tissues (Gao et al., 1998; Lee et al., 2000; Di Salvo et al., 2004). Recently, the three-dimensional structures of PLKs from bacteria and mammals, alone and in complex with various ligands were determined, providing a better understanding of the catalytic mechanism of PLK (Li et al., 2002, 2004; Safo et al., 2004, 2006; Tang et al., 2005; Cao et al., 2006). The active sites are structurally very similar among members of the ribokinase superfamily (Zhang et al., 2004). Therefore, the location and mode of substrate binding in human PLK have been deduced by analogy with the structures of sheep brain PLK in complex with various substrates (Cao et al., 2006).

Like mammals, insects rely on a nutritional source of $\mathrm{VB}_{6}$ to synthesize PLP. When newly moulted larvae of Bombyx mori are reared on a VB6-deficient diet, almost all of them died before moulting to the next instar (Huang et al., 1998). While the biological function of $\mathrm{VB}_{6}$ is similar in all organisms, there are differences between insects and mammals in $\mathrm{VB}_{6}$ metabolism. In mammals, PLP is first synthesized in the liver and then released into the bloodstream in association with albumin. Circulating PLP is dephosphorylated by membrane-associated phosphatase to gain entry into cells and is then converted back

\footnotetext{
* Corresponding author; e-mail: lqhuang218@yahoo.com.cn
} 
to PLP by intracellular PLK (Lumeng et al., 1980; Merrill et al., 1984). In a previous study on $\mathrm{VB}_{6}$ metabolism in $B$. mori larvae, it was found that dietary $\mathrm{PN}$ is absorbed by the midgut, then diffuses into the hemolymph and is actively transported to other organs. PN is first phosphorylated to PNP by PLK, which is then oxidized to PLP by PNPO in every larval organ except hemolymph (Zhang \& Huang, 2003). Since B. mori is a large silk-secreting insect, its immense protein turnover needs the timely support of PLP. In order to understand the metabolic mechanism of $\mathrm{VB}_{6}$ in $B$. mori, the cDNAs encoding PLK and PNPO in B. mori larvae were cloned (Shi et al., 2007; Huang et al., 2009). In this study, the recombinant $B$. mori PLK was expressed in E. coli as a fusion protein with a hexa-histidine affinity tag, purified by Ni Sepharose affinity column chromatography and characterized. The genomic organization and protein structure of $B$. mori PLK were also deduced by bioinformatics.

\section{MATERIAL AND METHODS}

\section{Material}

The $B$. mori PLK gene was from the vector pET-22b-BPLK, which was constructed in our laboratory (GenBank accession number: DQ452397). The E. coli strains Rosetta (DE3) and DH5 $\alpha$, and pfu DNA polymerase were purchased from Beijing TransGen Biotech (Beijing, China). Restriction enzymes (Nde I, Xho I), and T4 DNA ligase were purchased from TaKaRa (Dalian, China). A Gel Extraction Kit (SK1131), SYBR Green I, Isopropyl- $\beta$-D-thiogalactopyranoside (IPTG), DNA marker, protein marker, Coomassie brilliant blue G250/R250 and all other general reagents, were purchased from Sangon (Shanghai, China). Protease inhibitor cocktails, PLP, PMP-HCl, PNP, PL$\mathrm{HCl}, \mathrm{PM}-2 \mathrm{HCl}$ and $\mathrm{PN}-\mathrm{HCl}$ were purchased from SigmaAldrich (Shanghai, China). Ni Sepharose 6 Fast Flow and Millipore columns were purchased from GEHC (Shanghai, China) and Kenqiang (Shanghai, China), respectively. The primer construction was completed by Sangon Bio-technology Company (Shanghai, China).

\section{Gene subcloning}

Using pET-22b-BPLK as a template, the full coding region of the BPLK-gene was obtained by PCR reaction. The PCR reaction had a total volume of $50 \mu \mathrm{L}$, containing $1 \mu \mathrm{L}$ of templates, $5 \mu \mathrm{L}$ of $10 \times$ buffer, $200 \mu \mathrm{M}$ of each dNTP, $300 \mathrm{nM}$ of each primer, $5 \mathrm{U}$ of pfu DNA polymerase and $\mathrm{ddH}_{2} \mathrm{O} 39 \mu \mathrm{L}$. To take out the terminator contained in the coding region of BPLK, primers used in the PCR were as follows: sense primer (5'GGCCATATGTCTCAAGATGATACTCCA-3') and anti-sense primer (5'-GTCTCTCGAGGTTTATTTTCACAGCCTT-3'), which contained Nde I and Xho I recognition sites (underlined). Amplification was performed in a thermal-cycler (Y-Gradient Thermoblock, Biometra, Germany) as follows: $5 \mathrm{~min}$ at $94^{\circ} \mathrm{C}$; 30 cycles of $30 \mathrm{~s}$ at $94^{\circ} \mathrm{C}, 30 \mathrm{~s}$ at $55^{\circ} \mathrm{C}$ and $60 \mathrm{~s}$ at $72^{\circ} \mathrm{C}$, followed by $10 \mathrm{~min}$ at $72^{\circ} \mathrm{C}$. The PCR product was purified using DNA Gel Extraction kit, and digested with Nde I and Xho I restriction enzymes. The digested fragment was then purified again and ligated with T4 DNA ligase into pET-22b(+), previously digested with the same enzymes. The resulting recombinant plasmid was named pET-22b-BPLK-His, which contained a T7 promoter, B. mori PLK gene fused to a C-terminal hexahistidine affinity tag sequence and $\mathrm{T} 7$ terminator.

The plasmid was used to transform the competent cells of $E$. coli $\mathrm{DH} 5 \alpha$ for sequencing. The sequencing study was accomplished by Sangon Bio-technology Company (Shanghai, China) using the dye terminator method and an ABI 3730 automatic DNA sequencer.

\section{Protein expression and purification}

After the electrophoretic analysis and sequencing analysis of the DNA fragment, pET-22b-BPLK-His was used to transform E. coli Rosetta (DE3) cells for protein expression. The single bacterial colony of E. coli Rosetta (DE3), harbouring pET-22bBPLK-His, was cultured in $20 \mathrm{~mL}$ Luria-Bertani (LB) medium with ampicillin $(50 \mu \mathrm{g} / \mathrm{mL})$ and chloramphenicol $(3.4 \mu \mathrm{g} / \mathrm{mL})$ on a shaker platform, overnight, at $37^{\circ} \mathrm{C}$, and $4 \mathrm{~mL}$ of the overnight cultures was then inoculated into $400 \mathrm{~mL}$ LB medium with ampicillin $(50 \mu \mathrm{g} / \mathrm{mL})$ and chloramphenicol $(3.4 \mu \mathrm{g} / \mathrm{mL})$. The inoculum was grown at $37^{\circ} \mathrm{C}$ with vigorous shaking to an $\mathrm{OD}_{600}$, approximately $0.4-0.6$. IPTG was added to a final concentration of $1.0 \mathrm{mM}$ and the cells further incubated and shaken for $12 \mathrm{~h}$ at $16^{\circ} \mathrm{C}$. Cells were harvested by centrifugation $(6,347$ $\times \mathrm{g}$ at $4^{\circ} \mathrm{C}$ for $15 \mathrm{~min}$ ), re-suspended in cold $1 \times$ phosphatebuffered saline (PBS) (10 mM sodium phosphate, $\mathrm{pH} 7.4,140$ $\mathrm{mM}$ sodium chloride, $5 \mathrm{mM}$ potassium chloride) and collected by centrifugation $\left(6,347 \times \mathrm{g}\right.$ at $4^{\circ} \mathrm{C}$ for $\left.15 \mathrm{~min}\right)$.

The pellets were re-suspended in loading buffer $(20 \mathrm{mM}$ sodium phosphate, $\mathrm{pH} 7.4,20 \mathrm{mM}$ imidazole, $0.5 \mathrm{M} \mathrm{NaCl}$ ). Protease inhibitor cocktails were added according to the manufacturer's instruction. Unless otherwise specified, all subsequent steps were performed at $4{ }^{\circ} \mathrm{C}$. The suspensions were then broken up by sonication in ice and centrifuged at $12,840 \times \mathrm{g}$ for $10 \mathrm{~min}$.

For the purification, about $10 \mathrm{~mL}$ of the supernatant was loaded onto a chromatography column $(24 \mathrm{~mL})$ filled with $3 \mathrm{~mL}$ of Ni Sepharose and washed extensively with sodium phosphate buffer with increased imidazole concentration $(=150 \mathrm{mM})$ to remove un-specifically bound proteins, including E. coli PLK. Subsequently the histidine-tagged protein was eluted in $16 \mathrm{~mL}$ of sodium phosphate buffer containing $300 \mathrm{mM}$ imidazole. The purified B. mori PLK was concentrated to about $0.42 \mathrm{mg} / \mathrm{mL}$ with a Millipore (10,000 Da cut-off) in a buffer of $70 \mathrm{mM}$ potassium phosphate, $\mathrm{pH}$ 6.5. The above description is of a typical run.

The purity and homogeneity of the fractions and the subunit molecular weight of the PLK were estimated by 1-dimensional SDS-PAGE. Protein concentrations were determined by the method of Bradford using bovine serum albumin as standard. The molecular weight was determined by injecting approximately $3 \mathrm{mg}$ purified $B$. mori PLK into a Sephadex G-100 column $(1 \times 100 \mathrm{~cm})$. Samples of lysozyme, chymotrypsinogen, ovalbumin and hemoglobin were used as markers of known molecular weight. The elution buffer was $50 \mathrm{mM}$ Tris- $\mathrm{HCl}(\mathrm{pH}$ 7.5 ) and the flow rate $0.4 \mathrm{ml} / \mathrm{min}$.

\section{Assay of PLK activity}

Using PL as a substrate PLK activity was determined using the method of Sakurai (Sakurai et al., 1993) with some modifications. The formed product, PLP was determined by reaction with phenylhydrazine to enhance the sensitivity. Unless otherwise specified, all activity assays were performed three times. Purified enzyme (about $12 \mu \mathrm{g}$ ) was incubated at $37^{\circ} \mathrm{C}$ for 10 min in an assay buffer of $70 \mathrm{mM}$ potassium phosphate $(\mathrm{pH} 5.5)$ with $1.0 \mathrm{mM}$ PL, $1.0 \mathrm{mM}$ ATP and $0.5 \mathrm{mM} \mathrm{ZnCl}_{2}$ in a total volume of $1 \mathrm{~mL}$. The reaction was stopped by adding $100 \mu \mathrm{L}$ of $100 \%(\mathrm{w} / \mathrm{v})$ trichloroacetic acid, centrifuged at $11,400 \times \mathrm{g}$ for $10 \mathrm{~min}$ and any precipitate that formed discarded. One hundred micro liters of phenylhydrazine in $10 \mathrm{M}$ sulphuric acid was added to the mixture of $1 \mathrm{~mL}$ of supernatant and $2 \mathrm{~mL}$ of assay buffer. Enzyme activity was determined using a spectrophotometer at $410 \mathrm{~nm}$ for the first $2.5 \mathrm{~min}$ (Unico UV-2600 spectrophotometer, Unico instrument Co., Ltd, shanghai, China). The 


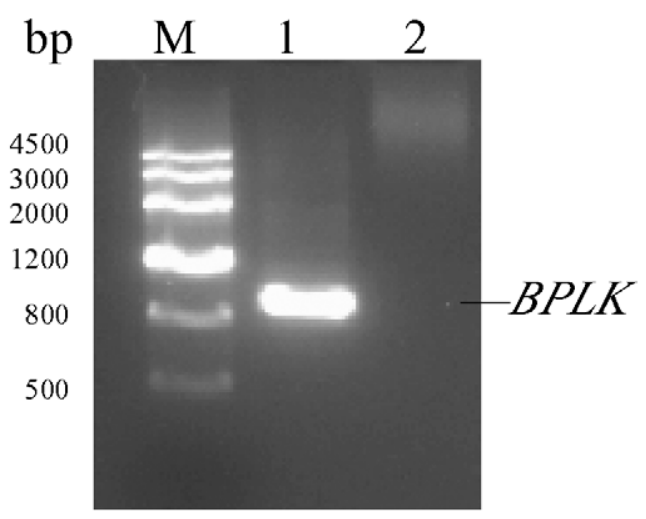

Fig. 1. Electrophoresis of the products of colony PCR. Lane $\mathrm{M}$ is DNA marker; Lane 1 is $B P L K$; Lane 2 is negative control.

blank was prepared by adding ATP after stopping the reaction with trichloroacetic acid. A unit of activity is defined as the nmol of PLP formed per minute per mg of protein at $37^{\circ} \mathrm{C}$. A standard curve of the absorbance at $410 \mathrm{~nm}$ against different concentrations of PLP standard was constructed for calculating the PLP generated in the enzyme assay.

The $\mathrm{pH}$ dependence of the PLK activity was measured between $\mathrm{pH} 4$ and 9, with an assay buffer of $70 \mathrm{mM}$ citric acid/potassium orthophosphate/boric acid solutions adjusted with $\mathrm{NaOH}$. Activity assays were performed at various $\mathrm{pHs}$ at $37^{\circ} \mathrm{C}$ for $10 \mathrm{~min}$. The effect of temperature on the PLK activity and stability were determined at temperatures from 20 to $55^{\circ} \mathrm{C}$. Activity was measured for $10 \mathrm{~min}$ at different temperatures. For stability assays, the enzyme was pre-incubated for $1 \mathrm{~h}$ at the indicated temperature, and residual activity was then assayed at $37^{\circ} \mathrm{C}$ as described above. Effect of divalent cations on the activity of the PLK was measured in the standard assay condition with $0.5 \mathrm{mM}$ of various divalent cations instead of $\mathrm{ZnCl}_{2}$.

To compute the enzyme kinetic data, about $10 \mu \mathrm{g}$ of the purified enzyme was used in each assay, and the concentrations of substrates were varied in the range $2-800 \mu \mathrm{M}$. At this enzyme concentration, the initial enzymatic rate was linear. Using PL as the variable substrate and ATP as the fixed substrate, the enzyme kinetic mechanism was estimated from double reciprocal plots.

\section{Analysis of genomic organization and protein structure of the enzyme}

The B. mori PLK cDNA (GenBank accession number: DQ452397) was used as the query to search the genomic database of B. mori (http://www.silkdb.org/, http://sgp.dna.affric. go.jp/) for the gene, and the gene structure was analyzed using software SeqVISTA (http://www.bio-soft.net/format.html).

Software Clustal W (http://www.ebi.ac.uk/clustalw/) was used to align amino acid sequences of PLKs from B. mori, humans, sheep, Arabidopsis thaliana, wheat and E. coli, whose PLK activities have been confirmed. These sequences have the following database accession numbers: B. mori, (GenBank) DQ452397; humans, (GenBank) U89606; sheep, (Swiss-Prot) P82197; A. thal, (GenBank) AF404865; wheat, (GenBank) AY33732 1; E coli, (Swiss-Prot) P40191.

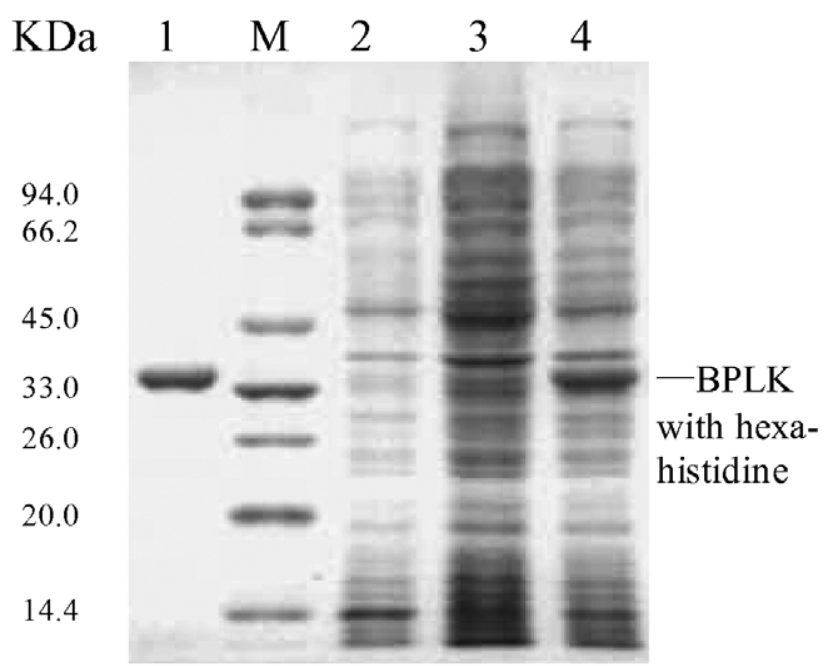

Fig. 2. SDS-PAGE (12\%) analysis of the recombinant $B$. mori PLK. Lane 1 is purified recombinant $B$. mori PLK; Lane M is molecular weight standard; Lane 2 is crude extract of $E$. coli Rosetta (DE3) harbouring pET22b(+); Lane 3 and 4 are crude extracts of $E$. coli Rosetta (DE3) harbouring pET22b-BPLK-His, induced by IPTG after $0 \mathrm{~h}$ and $12 \mathrm{~h}$, in that order.

The secondary structure of the purified PLK was quantitatively determined by circular dichroism (CD) spectrum analysis. Determination of CD spectrum was carried out on a JASCOJ810 spectropolarimeter (Jasco Corporation, Japan). The instrument conditions were as follows: measurement range, 260-190 $\mathrm{nm}$; data pitch, $0.2 \mathrm{~nm}$; data points, 351 ; band width, $3 \mathrm{~nm}$; response, $1 \mathrm{~s}$; sensitivity, standard; scanning speed, 100 $\mathrm{nm} / \mathrm{min}$; accumulation, 3 ; cell length, $0.1 \mathrm{~cm}$; temperature, room temperature; control and analysis software, Spectra Managermr. The purified PLK was dissolved in $50 \mathrm{mM}$ potassium phosphate (pH 7.4) buffer with a concentration of $0.1 \mathrm{mg} / \mathrm{mL}$.

The three-dimensional structure of $B$. mori PLK monomer was predicted by the method of homology modelling, using the human PLK (PDB accession number: 2YXT) as a template. Amino acid sequence was submitted to SWISS-MODEL server (http://www.swissmodol.expasy.crg/) for homology modelling. The result was analyzed by visual software Pymol ( http://www.bio-soft.net/3d/pymol.htm). The location and mode of substrate binding in $B$. mori PLK was deduced by analogy with the known crystal structures of mammalian PLK in complex with substrates.

\section{RESULTS}

\section{Recombinant expression and purification of $B$. mori PLK}

With the help of colony PCR, about a $900 \mathrm{bp}$ product was obtained from fusion expressional vector $\mathrm{pET}-22 \mathrm{~b}-$ BPLK-His (Fig. 1). DNA sequencing demonstrated that the PCR product had a $B$. mori $P L K$ gene and a $C$-terminal hexa-histidine tag sequence.

TABLE 1. Summary of the purification of recombinant $B$. mori PLK.

\begin{tabular}{ccccccc}
\hline Fraction & $\begin{array}{c}\text { Volume } \\
(\mathrm{mL})\end{array}$ & $\begin{array}{c}\text { Total protein } \\
(\mathrm{mg})\end{array}$ & $\begin{array}{c}\text { Protein concentration } \\
(\mathrm{mg} / \mathrm{mL})\end{array}$ & $\begin{array}{c}\text { Total activity } \\
(\mathrm{nmol} / \mathrm{min})\end{array}$ & $\begin{array}{c}\text { Activity } \\
(\mathrm{nmol} / \mathrm{min} / \mathrm{mL})\end{array}$ & $\begin{array}{c}\text { Specific activity } \\
(\mathrm{nmol} / \mathrm{min} / \mathrm{mg})\end{array}$ \\
\hline Crude preparation & 10 & 17.9 & 1.79 & 1253 & 125.3 & 70 \\
Purification & 1.3 & 0.57 & 0.44 & 1029 & 792 & 1800 \\
\hline
\end{tabular}



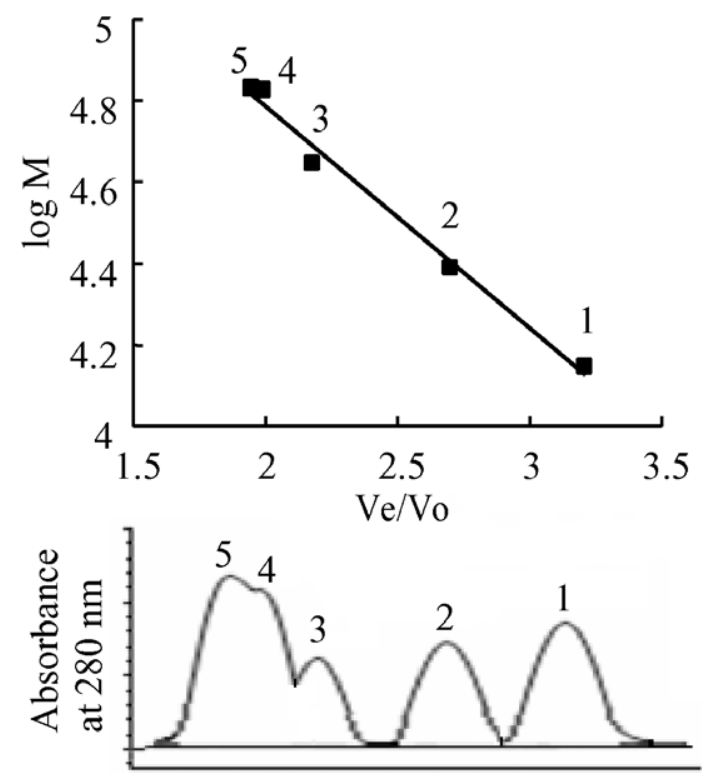

Fig. 3. Estimation of the molecular mass $(\mathrm{M}, \mathrm{kDa})$ of $B$. mori PLK by gel filtration using Sephadex G-100. 1 - lysozyme (14 $\mathrm{kDa}) ; 2$ - chymotrypsinogen $(25 \mathrm{kDa}) ; 3$ - ovalbumin $(44 \mathrm{kDa})$; 4 - hemoglobin (67 kDa); 5 - B. mori PLK. Ve - elution volume; Vo - outer volume.

Using the polyhistidine as a fusion tag, the over expressed protein was found in the soluble fraction. Using Ni Sepharose affinity column chromatography, the PLK was purified to over $90 \%$ homogeneity judged from 1-dimensional SDS-PAGE analysis (Fig. 2). Table 1 summarizes the purification of PLK. The enzyme was purified about 26-fold, and the final yield of the enzyme was $82 \%$ of the homogenate activity.

The dimeric PLK molecular mass was determined to be $68 \mathrm{kDa}$ by Sephadex G-100 gel filtration (Fig. 3). On a reducing SDS-PAGE gel (Fig. 2), the PLK, including one

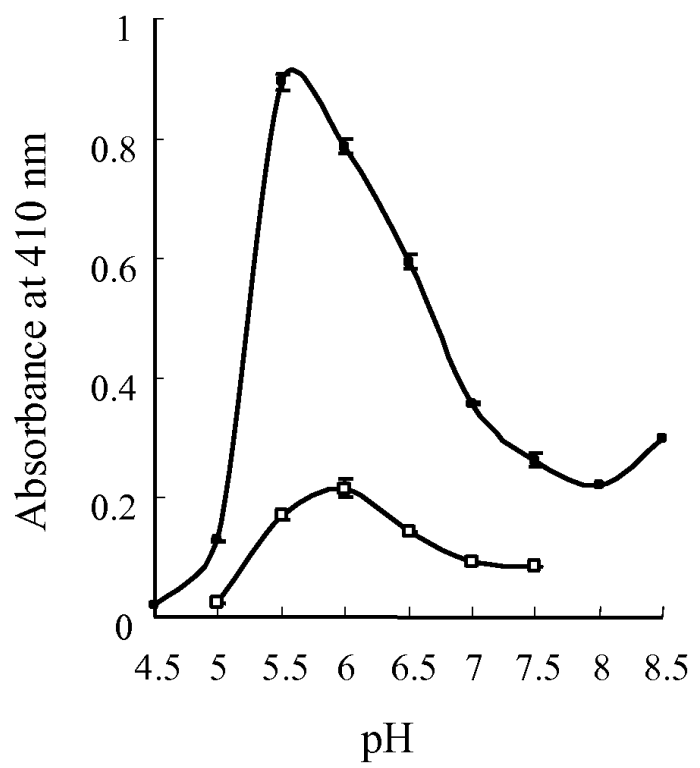

Fig. 4. Effect of $\mathrm{pH}$ on the catalytic activity of the recombinant $B$. mori PLK. Filled square $-\mathrm{pH}$ dependent assay with $\mathrm{Zn}^{2+}$, and open square $-\mathrm{pH}$ dependent assay with $\mathrm{Mg}^{2+}$.

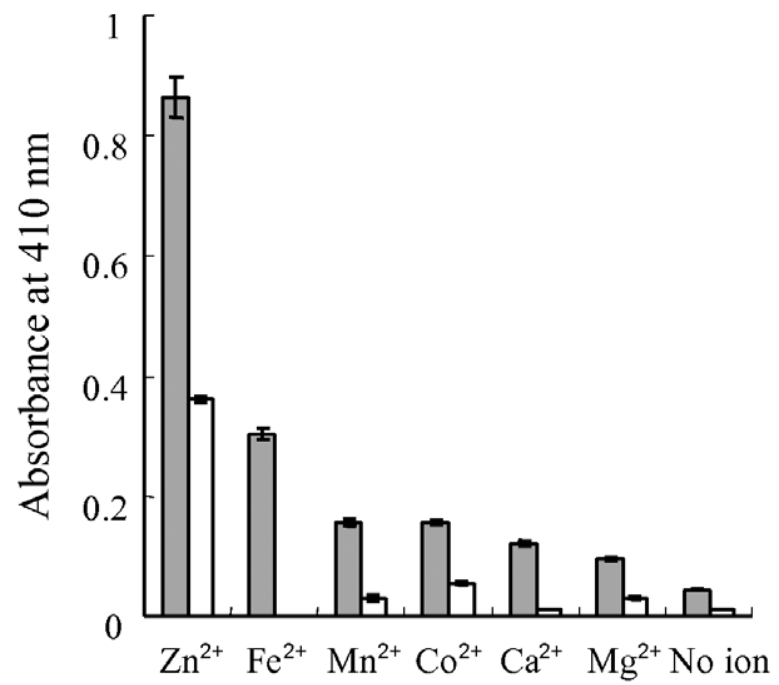

\section{Divalent ions}

Fig. 5. Effect of divalent cation on the activity of the recombinant $B$. mori PLK. Filled column - activity assay with phosphate buffer ( $\mathrm{pH} 5.5)$; open column - activity assay with triethanolamine buffer $(\mathrm{pH} 7.3)$.

$6 \times$ histidine tag in the C-terminus, appeared as a single band of about $33.9 \mathrm{kDa}$ computed by software of Quantity one (http://www.seekbio.com/soft/275.html) based on the protein marker. The data suggest that the recombinant PLK is a dimer with two identical subunits under native conditions.

\section{Catalytic properties of recombinant $B$. mori PLK}

Fig. 4 shows the effect of $\mathrm{pH}$ on the catalytic activity of the purified PLK. The PLK has maximum catalytic activity in the narrow $\mathrm{pH}$ range of 5.5-6.0 and with $\mathrm{Zn}^{2+}$, and the enzyme was inactive below $\mathrm{pH}$ 4.5. Enzyme activity decreased slowly above $\mathrm{pH}$ 6.0, to approximately

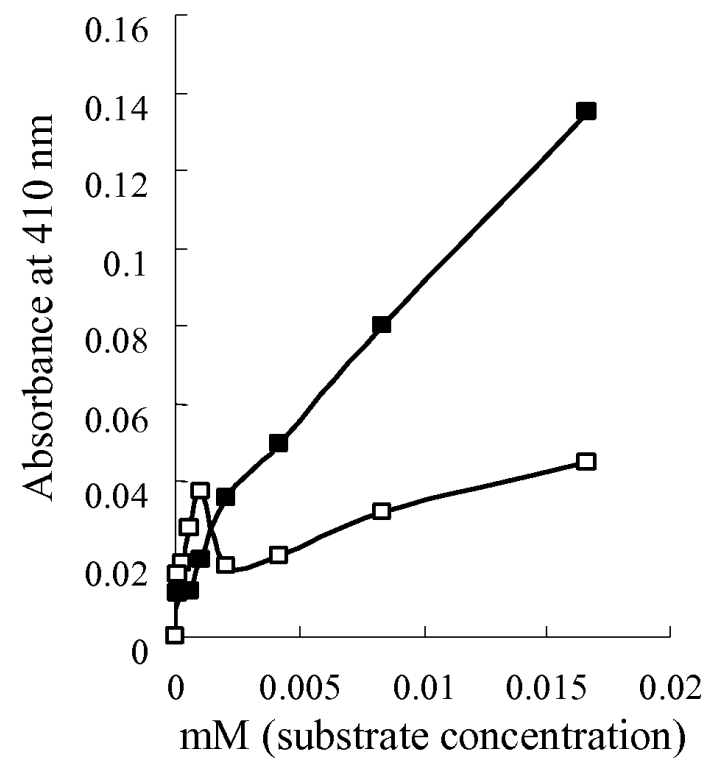

Fig. 6. Effect of $\mathrm{Zn}^{2+}$ and $\mathrm{Mg}^{2+}$ at different physiological substrate concentrations on the activity of the recombinant $B$. mori PLK. Filled square $-\mathrm{Zn}^{2+}$; open square $-\mathrm{Mg}^{2+}$. 


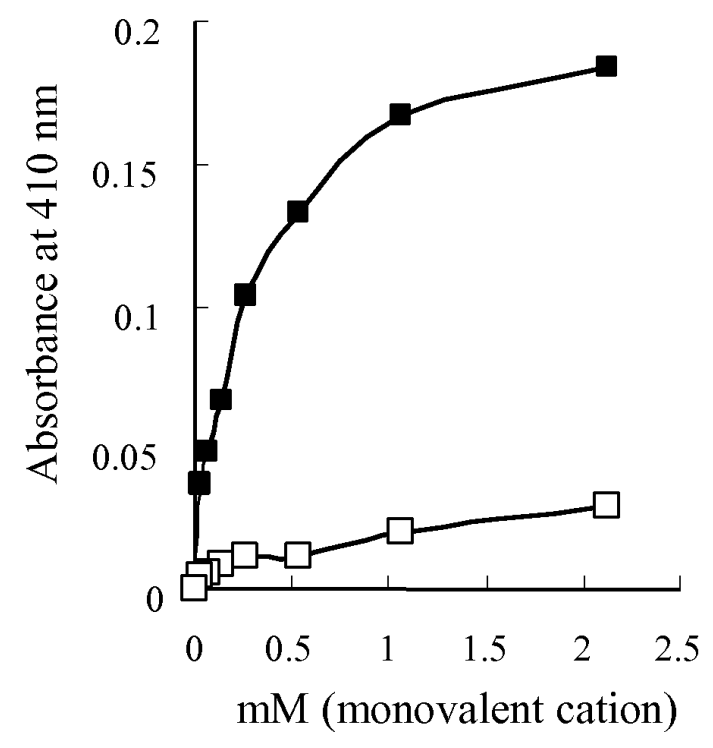

Fig. 7. Activity of B. mori PLK in the presence of either $\mathrm{K}^{+}$or $\mathrm{Na}^{+}$. Monovalent cation was added in increasing concentrations to the PLK in triethanolamine buffer ( $\mathrm{pH}$ 7.3). Filled square $\mathrm{K}^{+}$; open square $-\mathrm{Na}^{+}$.

$35 \%$ at $\mathrm{pH}$ 8.5. Performing the $\mathrm{pH}$ dependent assay with $\mathrm{Mg}^{2+}$, the optimum $\mathrm{pH}$ for the PLK activity was 6.0. The enzyme displayed optimal activity at $50^{\circ} \mathrm{C}$, and its greatest stability was below $40^{\circ} \mathrm{C}$ (data not shown). At $\mathrm{pH} 5.5$ and $37^{\circ} \mathrm{C}$, the time course of enzyme activity was linear for up to $40 \mathrm{~min}$ (data not shown).

Figs 5 and 6 show the effect of divalent cation on PLK activity. Under saturating PL and ATP concentrations, $\mathrm{Zn}^{2+}$ is the most efficient cation for catalysis, analyzed with phosphate buffer ( $\mathrm{pH}$ 5.5) or triethanolamine buffer (pH 7.3). At about a $1 \mu \mathrm{M}$ substrate concentration, $\mathrm{Mg}^{2+}$, however, stimulates the activity (Fig. 6). Enzyme activity was also measured using a monovalent cation at saturating PL and ATP concentrations, which revealed that $\mathrm{K}^{+}$ is an activator of PLK when only triethanolamine is present as the cation (Fig. 7). If instead of the phosphate buffer an acetate buffer is used, enzymatic activity was reduced to $74 \%$ and almost no activity was recorded when a citrate buffer was used (Fig. 8).

An initial velocity study using PL as the variable substrate and ATP as the fixed substrate gave a family of lines intersecting to the left of the vertical axis (Fig. 9), which eliminated the possibility of a ping-pong catalytic mechanism. Such an intersecting pattern suggests that the enzyme catalyzes the reaction by means of a sequential catalytic mechanism. As the point of intersection of the lines is below the horizontal axis, it reveals that the com-

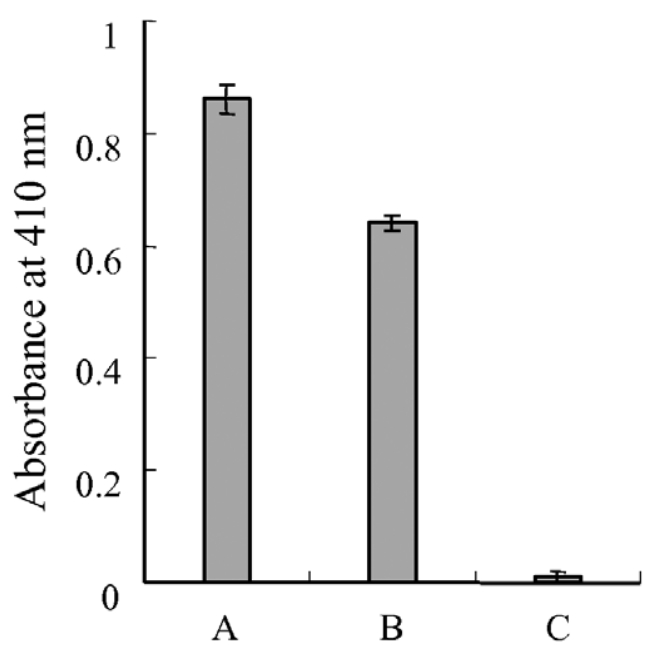

Fig. 8. Assays of B. mori PLK activity using $70 \mathrm{mM}$, pH 5.5 sodium phosphate buffer (A), sodium acetate buffer (B) and sodium citrate buffer $(\mathrm{C})$.

bination of fixed substrate and enzyme affects the $\mathrm{Km}$ value of the variable substrate, which increases with increase in the concentration of the fixed substrate. Under optimal conditions, the $\mathrm{Km}$ values of PLK for ATP and $\mathrm{PL}$ were determined as $57.9 \pm 5.1$ and $44.1 \pm 3.9 \mu \mathrm{M}$. Table 2 summarizes the kinetic parameters of PLK including the $K \mathrm{~m}, V \max , k$ cat and $k$ cat $/ K \mathrm{~m}$.

\section{Genomic organization of $B$. mori PLK}

Using cloned B. mori PLK cDNA as a query to search against the $B$. mori genomic database (http://www.silkdb.org/), the PLK gene was located at nscaf2828:3863864-3871593 with gene number BGIBMGA005472-TA. From the other B. mori genomic database (http://sgp.dna.affric.go.jp/), the $P L K$ gene was located at chr8:11034281-11042010Bm_scaf19:38701643877893 with gene number BGIBMGA005472. The two genomic databases gave the same result. B. mori contains a single copy of the PLK gene on the eighth chromosome and no other homologous genes were found. The PLK gene spans a region about $7.73 \mathrm{~kb}$ long, and contains five exons and four introns (Fig. 10). Within the region from -26 to -68 , relative to the transcription start site (-CCATAT-), typical TATA-like and CAAT-like boxes are identified. All exon/intron boundaries contain the canonical 5' donor GT and 3' acceptor AG sequences. At the 3' region of the $P L K$ gene, some A-tailing sequences were identified.

TABLE 2. Kinetic data of recombinant B. mori PLK.

\begin{tabular}{|c|c|c|c|c|}
\hline Substrate & $K \mathrm{~m}(\mu \mathrm{M})$ & $\begin{array}{c}V \max \\
\left(\mu \mathrm{mol} \text { PLP } \min ^{-1} \mathrm{mg}^{-1}\right)\end{array}$ & $k$ cat $\left(\mathrm{S}^{-1}\right)$ & $k \mathrm{cat} / \mathrm{Km}\left(\mathrm{M}^{-1} \mathrm{~S}^{-1}\right)$ \\
\hline ATP & $57.9 \pm 5.1$ & $2.23 \pm 0.25$ & 1.23 & $2.12 \times 10^{4}$ \\
\hline PL & $44.1 \pm 3.9$ & $2.45 \pm 0.28$ & 1.35 & $3.06 \times 10^{4}$ \\
\hline
\end{tabular}

Assay conditions were $2.0 \mathrm{mM}$ fixed substrate, $2-800 \mu \mathrm{M}$ variable substrate, $0.5 \mathrm{mM} \mathrm{ZnCl}_{2}, 70 \mathrm{mM}$ potassium phosphate ( $\mathrm{pH} 5.5$ ), $10 \mu \mathrm{g}$ of protein, at $37^{\circ} \mathrm{C}$ for $10 \mathrm{~min}$. 


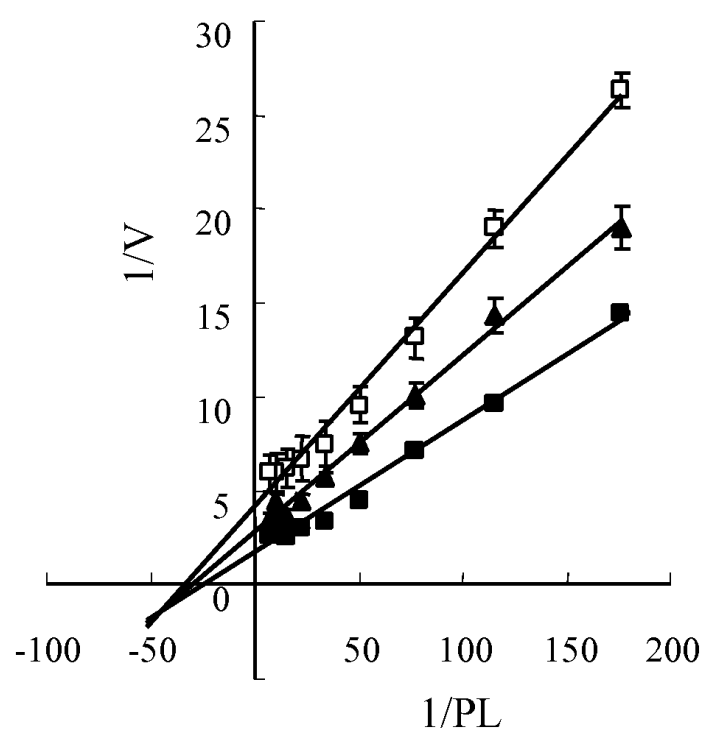

Fig. 9. Kinetic analysis of recombinant B. mori PLK. Using $\mathrm{PL}$ as the variable substrate and ATP as the fixed substrate. Open square $-0.04 \mathrm{mM}$ ATP; filled triangle $-0.2 \mathrm{mM}$ ATP; filled square $-1 \mathrm{mM}$ ATP.

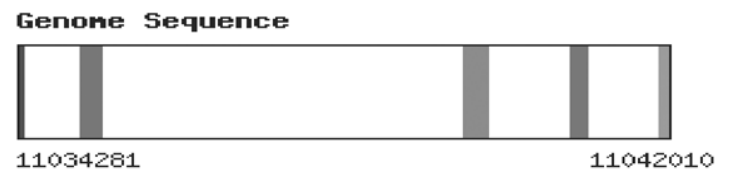

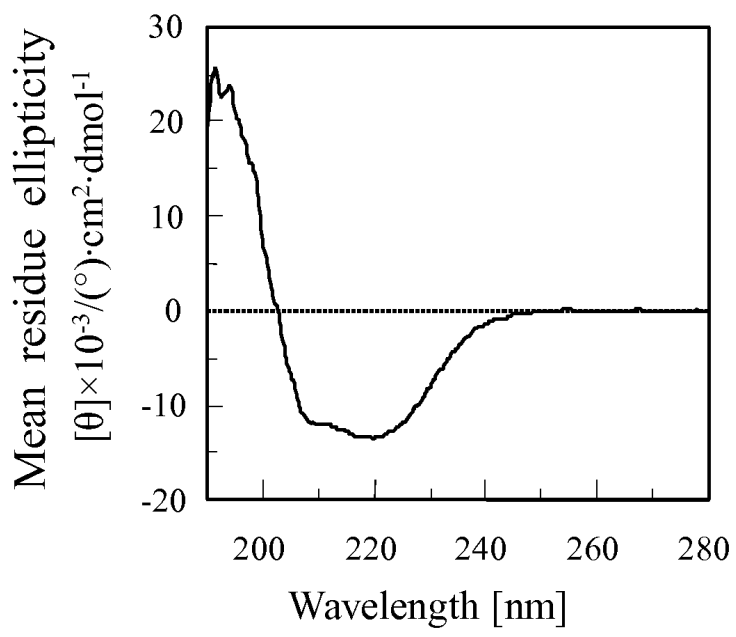

Fig. 11. Circular dichroism spectrum of recombinant B. mori PLK.

coli, respectively. B. mori PLK contains conserved amino acid sequence motifs that may be involved in substrate binding or catalysis of the PLK family. A distinctive characteristic of B. mori PLK is that its sequence is 10 or

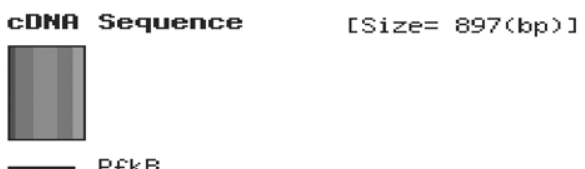

Fig. 10. Schematic diagram of the exon / intron organization of B. mori PLK gene obtained from B. mori genomic database (http://sgp.dna.affric.go.jp/).

\section{Protein structure of $\boldsymbol{B}$. mori PLK}

Fig. 11 shows the circular dichroism spectra of the purified PLK. The relative percentage content of each secondary structure was: $43.1 \pm 3.5 \% \alpha$-helix, $18.5 \pm 2.3 \%$ $\beta$-sheet, $14.7 \pm 0.8 \% \beta$-turn and $23.6 \pm 1.1 \%$ random coil respectively, computed by the circular dichroism spectrometer's software. The secondary structure content matched the theoretical analysis by software Psipred, which reveals that the purified PLK was not mis-folded. The secondary structure content of $B$. mori PLK is also similar to that of mammalian PLKs with threedimensional structures (Table 3).

Fig. 12 shows the amino acid sequence alignment of $B$. mori, human, sheep, A. thaliana, wheat and E. coli PLKs. The $B$. mori PLK contains 298 amino acid residues with a theoretical molecular mass of $33.1 \mathrm{kDa}$ and $\mathrm{pI}$ value of about 6.3 . The amino acid sequence shares a $50 \%$ identity with that of human PLK, and $48 \%$ with sheep, $46.7 \%$ with $A$. thaliana, $44.48 \%$ with wheat and $32 \%$ with $E$. more residues shorter than that of PLK from mammals and plants. Compared with B. mori PLK, the sequence exhibits extension of the N-terminal in plants, and increase in nonconservative residues in mammal. Secondly, the key peptide loop, which is thought to play a significant role in the functioning of PLK (Safo et al., 2006), consists of eight residues in B. mori PLK and 12 in mammals.

Fig. 13 (B) shows the monomer structure of $B$. mori PLK, predicted using homology modelling, with the help of software Pymol (http://www.bio-soft.net/3d/pymol. $\mathrm{htm})$. Each monomer consists of eight $\alpha$-helices $(\alpha 1-8)$, nine $\beta$-strands $(\beta 1-9)$ and two segments of $3_{10}$ helices. The 1-8 $\beta$-strands constitute a central contorted $\beta$-sheet flanked by $\alpha 2, \alpha 3, \alpha 4, \alpha 5$ and $\alpha 6$ on one side, and $\alpha 1, \alpha 7$ and $\alpha 8$ on the other side. The overall folding pattern is a $\alpha \beta \alpha$ three-layer sandwich, which is common in the ribokinase super-family.

TABLE 3. Comparison of the secondary structure components of human, sheep, E. coli and B. mori PLKs.

\begin{tabular}{cccccc}
\hline Species & PDB accession number & amino acid residues & $\alpha$-helix & $\beta$-sheet & $\beta$-turn and random coil \\
\hline Human* & 2 YXT & 312 & $38 \%$ & $19 \%$ & $43 \%$ \\
Sheep* & 1LHP & 312 & $39 \%$ & $18 \%$ & $43 \%$ \\
B. mori $^{* *}$ & & 298 & $42 \%$ & $19 \%$ & $39 \%$ \\
\hline
\end{tabular}

\footnotetext{
* With known crystal structure; ** Predicted by software Psipred (http://bioinf.cs.ucl.ac.uk/psipred/)
} 


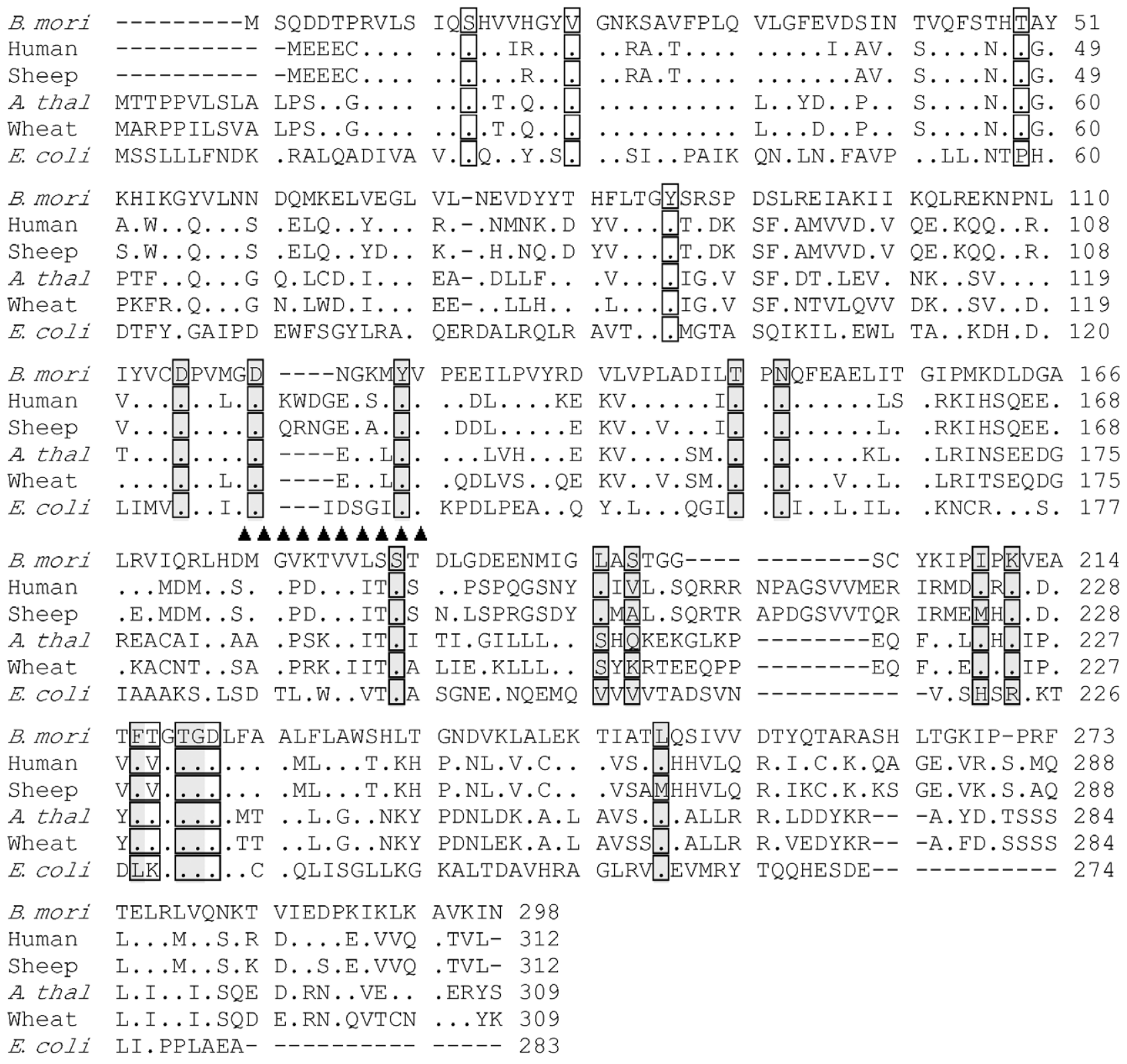

Fig. 12. Sequence alignment of PLKs from B. mori, humans, sheep, A. thaliana, wheat and E. coli. Dots for identical residues, dashes gaps introduced to maximize similarity. The key peptides of loop are marked by filled triangles. ATP-binding site and PLbinding site are boxed, and ATP-binding site is coloured grey.

Fig. 13 (C) shows the location and mode of substrate binding in $B$. mori PLK deduced by analogy with the structures of sheep brain PLK in complex with various substrates (Li et al., 2002, 2004). On the enzyme surface, there is a cavity with a negative charge located along one edge of the central $\beta$-sheet and this high negative charge attracts substrates with a positive charge, such as the pyridine ring of $\mathrm{VB}_{6}$ and the adenine ring of ATP, which bind there. The ATP-binding site is positioned in a shallow groove formed by the hydrophobic side chains of surrounding residues. Residues that interact with the phosphate groups of ATP are $\mathrm{Ser}^{185}, \mathrm{Thr}^{146}, \mathrm{Asp}^{115}, \mathrm{Asn}^{148}$, $\mathrm{Asp}^{120}$, Gly ${ }^{220}, \mathrm{Tyr}^{125}$ and $\mathrm{Thr}^{219}$; and residues Leu ${ }^{197}$, Lys $^{211}$, Phe ${ }^{216}$, Ser ${ }^{199}$, Ile ${ }^{209}$ and $\mathrm{Leu}^{249}$ interact with the adenine ring of ATP. The PL-binding site is located in a pocket in the opposite direction of ATP, and consists of $\mathrm{Tyr}^{86}, \mathrm{Val}^{21}, \mathrm{Thr}^{217}, \mathrm{Ser}^{14}, \mathrm{Thr}^{49}$ and $\mathrm{Asp}^{221}$.

\section{DISCUSSION}

A large number of genes/cDNAs encoding PLK have been isolated from mammals, microorganisms and plants, and their sequences submitted to the GenBank. A sequence homology search using the Dnaman program found several close homologs of PLK, from both prokaryotes and eukaryotes. The sequence identity with the human enzyme ranges from $24 \%$ to $90 \%$. The amino acid sequence of $B$. mori PLK shares a $50 \%$ identity with that of human PLK.

In mammals, PLK is a dimer of identical subunits, each with an estimated molecular mass of approximately 35 $\mathrm{kDa}$. The dimer can dissociate reversibly into catalytically 

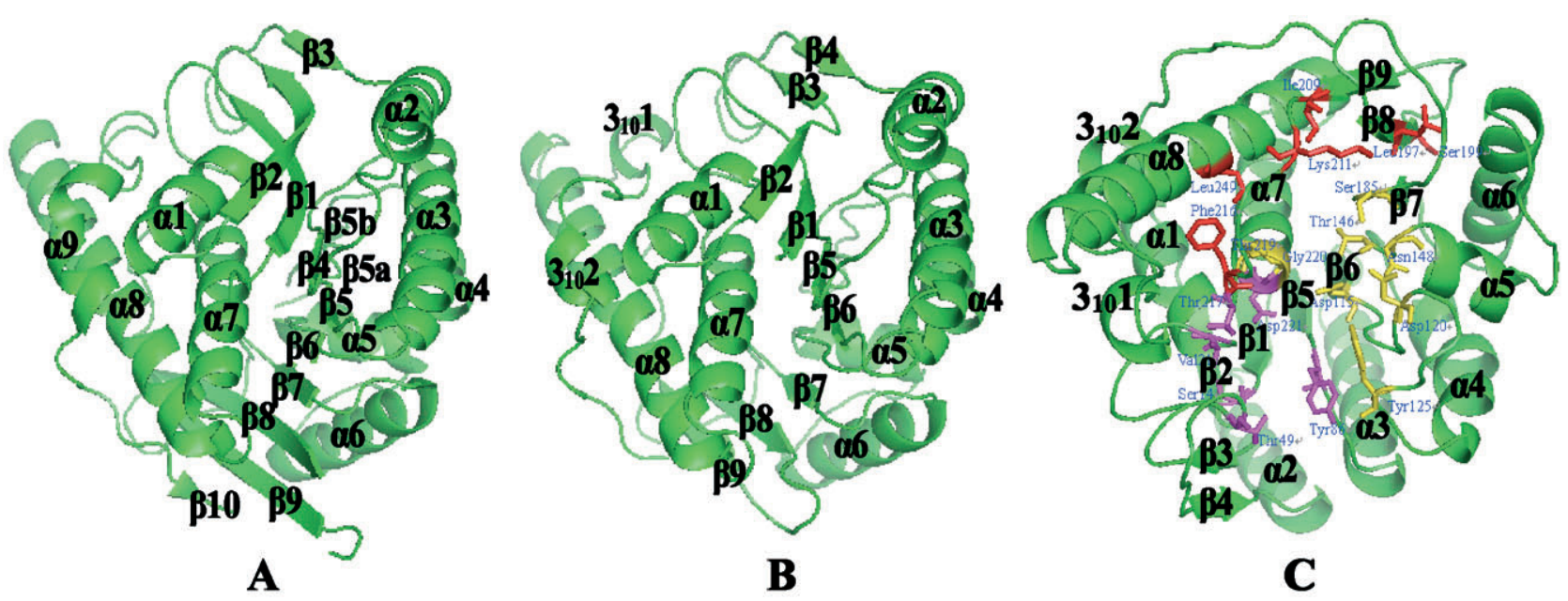

Fig. 13. A - Monomer structure of human PLK obtained from PDB database with the help of visual software Pymol. B Monomer structure of $B$. mori PLK predicted by homology modelling. C - Monomer structure of $B$. mori PLK with active site. The ATP phosphate group-binding site, ATP adenine ring-binding site and PL-binding site are coloured yellow, red and purple, respectively.

active monomers (Kwok et al., 1987). As in mammals, the $B$. mori PLK also may be a dimer with two identical subunits under native conditions. The monomer molecular mass of B. mori PLK, however, is $33.1 \mathrm{KDa}$ and smaller than the mammalian counterpart.

Previous structural analysis of sheep brain PLK complexes reveals that there is a key 12-residue loop (Gly-117 to Val-128) over the active site, which has an important role in the catalytic process. After ATP binding, the loop partially covers the ATP-binding site and prevents the unproductive hydrolysis of ATP; when substrates are absent, the loop exhibits a different conformation and occupies neither the ATP-binding site nor the PL-binding site (Li et al., 2002, 2004; Tang et al., 2005). The conformation of the corresponding segment in human PLK is not a loop, but a $\beta$-strand/loop/ $\beta$-strand flap (Cao et al., 2006). A multiple sequence alignment of PLKs from different species (Fig. 12) indicates that the key peptides in $B$. mori consist of eight residues, similar to that in plants and E. coli. It is suggested that the length and conformation of the peptide might serve as an indicator of where it is along the evolutionary pathway of the PLK family from simple to complex.

The structure of the PLK active site is well studied in mammals (Li et al., 2002, 2004; Cao et al., 2006). Shared by human and sheep, the residues that interact with the phosphate groups of ATP are $\mathrm{Ser}^{187}, \mathrm{Thr}^{148}, \mathrm{Asp}^{113}, \mathrm{Asn}^{150}$, $\mathrm{Asp}^{118}$, Gly ${ }^{234}$, Tyr ${ }^{127}$ and $\mathrm{Thr}^{233}$. The residue $\mathrm{Tyr}^{84}$ is on one side of the pyridine ring of $\mathrm{PL}$ and makes a $\pi$-interaction with the pyridine ring, whereas $\mathrm{Val}^{231}$ and $\mathrm{Val}^{19}$ are on the other side, interacting with PL by a hydrophobic effect. The N-1, O-3 and O-5 atoms of PL form hydrogen bonds and hydrophobic interact with the side chains of $\mathrm{Ser}^{12} \mathrm{Thr}^{47}$ and $\mathrm{Asp}^{235}$, respectively. Residues $\mathrm{Val}^{41}$, $\mathrm{Phe}^{43}, \mathrm{Val}^{14}$, $\mathrm{Val}^{56}$, $\mathrm{Trp}^{52}$ and $\mathrm{Val}^{115}$ all contribute to forming a hydrophobic environment for the binding of PL to the active site; especially $\mathrm{Tyr}^{84}, \mathrm{Asp}^{235}$ and $\mathrm{Ser}^{12}$, share the function of determining substrate specificity. All of these important residues are found to be conserved in B. mori PLK, except $\mathrm{Val}^{231}$ and $\operatorname{Trp}^{52}$. The residue Val is replaced by $\mathrm{Thr}$ in plants and B.mori PLK, whereas Trp is replaced by Ile in B. mori PLK.

Residues $\mathrm{Ala}^{201}, \mathrm{Met}^{223}$ and $\mathrm{Met}^{263}$, which interact with the adenine ring of ATP in sheep brain PLK through hydrophobic interactions, are substituted, respectively, in human PLK by more hydrophobic amino acids $\mathrm{Val}^{201}$, $\mathrm{Ile}^{223}$ and $\mathrm{Leu}^{263}$ (Cao et al., 2006). In B. mori PLK, the residues are replaced by Gly, Ile and Leu, respectively. It is suggested that like human PLK, B. mori PLK has more affinity with ATP than sheep PLK. In addition, Asn ${ }^{121}$, which has a positive charge over the ATP-binding site in sheep brain PLK, is replaced by negative charged residue $\mathrm{Asp}^{121}$, and the residue $\mathrm{Arg}^{120}$ in the key peptide loop of sheep brain PLK is replaced by $\operatorname{Trp}^{120}$ in human PLK (Cao et al., 2006). Two amino acid residue positions are found to be absent from B. mori PLK. Moreover, residue $\mathrm{Asn}^{45}$ in human PLK is conserved among all species aligned in this research, but is substituted by Thr in $B$. mori PLK. A key residue His ${ }^{59}$ in E. coli PLK, interacts with the aldehyde group at C-4 of PL and may also determine if residues from the key peptide loop can fill the active site in the absence of the substrate (Safo et al., 2006). The residue His is substituted by Ala in $B$. mori PLK.

In E. coli, the metal ion $\mathrm{Mg}^{2+}$ and $\mathrm{K}^{+}$are required for enzyme activity ( $\mathrm{Li}$ et al., 2002; Safo et al., 2006). In contrast, $\mathrm{Zn}^{2+}$ and $\mathrm{K}^{+}$have been proposed to be the metal ions needed for the activity of both human PL and sheep PL kinases (Li et al., 2002). However, a more recent study of the human enzyme showed that at non-physiological concentrations of the substrate and/or at $\mathrm{pH} 6$, at which the previous assays were performed, $\mathrm{Zn}^{2+}$ does stimulate activity (McCormick et al., 1961; White \& Dempsey, 1970), but under physiological conditions at $\mathrm{pH} 7.3, \mathrm{Mg}^{2+}$ is the required divalent metal ion and $\mathrm{Zn}^{2+}$ inhibits the reaction (Di Salvo et al., 2004). At saturating PL and ATP concentrations, both $\mathrm{Na}^{+}$and $\mathrm{K}^{+}$activate human PLK, with $\mathrm{Na}^{+}$resulting in a six-fold increase in activity 
TABLE 4. Genomic organization of B. mori, human, A. thaliana, malarial parasite and E. coli PLKs.

\begin{tabular}{ccccccccc}
\hline Species & $\begin{array}{c}\text { Accession } \\
\text { number }\end{array}$ & $\begin{array}{c}\text { Chromosomal } \\
\text { localization }\end{array}$ & Span $(\mathrm{pb})$ & Exon (pb) & $\begin{array}{c}\text { Exon } \\
(\mathrm{piece})\end{array}$ & cDNA (pb) & $\begin{array}{c}\text { Open reading } \\
\text { frame }(\mathrm{pb})\end{array}$ & $\begin{array}{c}\text { Amno } \\
\text { acid }\end{array}$ \\
\hline B. mori & DQ452397 & 8 & 7729 & 993 & 5 & 915 & 897 & 298 \\
Human* & NM_003681.4 & 21 & 43000 & 7366 & 11 & 1210 & 939 & 312 \\
A. thaliana* & AF400125.1/AF404865 & 5 & 3428 & - & 13 & 930 & 930 & 309 \\
Malaria parasite* & NP_7038201.1 & 6 & 1773 & 1494 & 3 & 1494 & 1494 & 497 \\
E. coli* & AP009048.1 & - & 852 & 852 & - & 852 & 852 & 283 \\
\hline
\end{tabular}

* Data from NCBI database (http://www.ncbi.nlm.nih.gov/)

and $\mathrm{K}^{+}$only a 2.5 -fold increase (Musayev et al., 2007). When the activity of the recombinant $B$. mori PLK using monovalent cations under saturating PL and ATP concentrations was measured it was found that $\mathrm{K}^{+}$is also an activator of the enzyme, whereas $\mathrm{Na}^{+}$did not activate PLK. The $\mathrm{pH}$ dependent study with $\mathrm{Mg}^{2+}$ and $\mathrm{Zn}^{2+}$ showed optimum enzyme activity at $\mathrm{pH} 6.0$ and 5.5 , respectively, with the $\mathrm{Zn}$ enzyme exhibiting more activity. At $\mathrm{pH} 7.3$ with triethanolamine buffer, $\mathrm{Zn}^{2+}$ was still the most effective divalent cation for the catalysis of $B$. mori PLK. This data suggest that the optimal activity of $B$. mori PLK is recorded in acidic environments. Under physiological substrate concentrations, $\mathrm{Mg}^{2+}$ slightly stimulated the activity of $B$. mori PLK. It was not possible to detect inhibition by $\mathrm{Zn}^{2+}$ because the substrate concentrations were so low that the initial velocity could not be measured accurately. The mechanism of phosphorylation has been elucidated for sheep and E. coli enzymes, and follows a random sequential substrate addition (Li et al., 2002, 2004; Safo et al., 2004, 2006). Using PL as the variable substrate and ATP as the fixed substrate, a double reciprocal plot of initial velocity also suggests a sequential catalytic mechanism for the B. mori PLK.

Each human PLK monomer contains nine $\alpha$-helices and $12 \beta$-strands (Cao et al., 2006) (Fig. 13 A). Sheep brain PLK monomer contains $9 \alpha$-helices, $10 \beta$-strands and 3 segments of $3_{10}$ helices (Li et al., 2002). The monomer of PLK from a prokaryote cell encoded by a $p d x K$ gene consists of eight $\alpha$-helices and nine $\beta$-strands (Safo et al., 2006). It is hypothesized, based on homology modelling, that the B. mori PLK monomer contains eight $\alpha$-helices $(\alpha 1-8)$, nine $\beta$-strands ( $\beta 1-9)$ and two segments of $3_{10}$ helices.

Table 4 summarizes the genomic organization of PLKs from $B$. mori, human, A. thaliana, malarial parasite and $E$. coli. The human PLK gene and that of $A$. thaliana contain more than ten exons, and that of $B$. mori and the malarial parasite five and three exons, respectively. The $B$. mori PLK gene has shorter introns than the human PLK gene. These differences may be related to the evolution of the PLK family and the complexity of the regulation of PLK gene expression.

In conclusion, the results of recombinant expression, purification and characterization of B. mori PLK are presented. This is the first report on the characterization of a PLK in insects. B. mori PLK contains signatureconserved amino acid sequence motifs of the PLK family. The catalytic properties and protein structure of B. mori
PLK are similar to those of human PLK in terms of mass, but some distinguishing feature of the PLK was also observed in this study.

ACKNOWLEDGMENTS. This study was funded by the National Natural Science Foundation of China (No. 30870338).

\section{REFERENCES}

Cao P., Gong Y., Tang L., Leung Y.C. \& Jiang T. 2006: Crystal structure of human pyridoxal kinase. J. Struct. Biol. 154: 327-332.

Di Salvo M.L., Hunt S. \& Schirch V. 2004: Expression, purification and kinetic constants for human and Escherichia coli pyridoxal kinases. Protein Expr. Purif. 36: 300-306.

Gao Z.G., Lau C.K., Lo SC., Choi S.Y., Churchich J.E. \& KwoK E. 1998: Porcine pyridoxal kinase cDNA cloning, expression and confirmation of its primary sequence. Int. $J$. Biochem. Cell Biol. 30: 1379-1388.

Hanna M.C., Turner A.J. \& Kirkness E.E. 1997: Human pyridoxal kinase. cDNA cloning, expression, and modulation by ligands of the benzodiazepine receptor. J. Biol. Chem. 272: 10756-10760.

Huang L.Q., Zhang J.Y., HayaKawa T.S. \& Tsuge H.H. 1998: Vitaminic response of the silkworm, Bombyx mori fed the synthetic diet with different amounts of pyridoxine. J. Seric. Sci. Jpn 67: 9-15.

Huang S.H., Shi R.J., Zhang J.Y. \& Huang L.Q. 2009: Cloning and characterization of a pyridoxine 5'-phosphate oxidase from silkworm, Bombyx mori. Insect Mol. Biol. 18: 365-371.

Kerry J.A. \& KwoK E. 1986: Purification and characterization of pyridoxal kinase from human erythrocytes. Prep. Biochem. 16: 199-216.

Kerry J.A., Rohde M. \& KwoK E. 1986: Brain pyridoxal kinase. Purification and characterization. Eur. J. Biochem. 158: 581-585.

Kwok F. \& Churchich J.E. 1979: Brain pyridoxal kinase. purification, substrate specificities, and sensitized photodestruction of an essential histidine. J. Biol. Chem. 254: 6489-6495.

Kwok F., Scholz G. \& Churchich J.E. 1987: Brain pyridoxal kinase dissociation of the dimeric structure and catalytic activity of the monomeric species. Eur. J. Biochem. 168: 577-583.

Lee H.S., Moon B.J., Choi S.Y. \& Kwon O.S. 2000: Human pyridoxal kinase: over expression and properties of the recombinant enzyme. Mol. Cells 10: 452-459.

Li M.H., Kwok F., Chang W.R., Lau C.K., Zhang J.P., Lo S.C.L., JiANG T. \& LiANG D.C. 2002: Crystal structure of brain pyridoxal kinase, a novel member of the ribokinase superfamily. J. Biol. Chem. 277: 46385-46390.

Li M.H., Kwok F., Chang W.R., Lau C.K., Lo S.C.L., Zhang J.P., JiAng T. \& Liang D.C. 2004: Conformational changes in the reaction of pyridoxal kinase. J. Biol. Chem. 279: $17459-17465$. 
Lum H.K., Kwok F. \& Lo S.C. 2002: Cloning and characterization of Arabidopsis thaliana pyridoxal kinase. Planta 215: 870-879.

Lumeng L., Lui A. \& Li T.K. 1980: Plasma content of b 6 vitamers and its relationship to hepatic vitamin b 6 metabolism. J. Clin. Invest. 66: 688-695.

Maras B., Valiante S., Orru S., Simmaco M., Barra D. \& Churchich J.E. 1999: Structure of pyridoxal kinase from sheep brain and role of the tryptophanyl residues. J. Protein Chem. 18: 259-268.

McCormick D.B., Gregory M.E. \& Snell E.E. 1961: Pyridoxal phosphokinases. 1. Assay, distribution, and properties. J. Biol. Chem. 236: 2076-2084.

Merrill A.H., Henderson J.M., Wang E., Mcdonald B.W. \& MilliKAN W.J. 1984: Metabolism of vitamin $\mathrm{B}_{6}$ by human liver. J. Nutr. 114: 1664-1674.

Musayev F.N., di Salvo M.L., Ko T.P., Gandhi A.K., Goswaml Q. \& Schirch V. 2007: Crystal structure of human pyridoxal kinase: Structural basis of $\mathrm{M}^{+}$and $\mathrm{M}^{2+}$ activation. Protein Sci. 16: 4542-4552.

Safo M.K., Musayev F.N., Hunt S., di Salvo M.L., Scarsdale N. \& SCHIRCH V. 2004: Crystal structure of the pdxy protein from Escherichia coli. J. Bacteriol. 186: 8074-8082.

Safo M.K., Musayev F.N., di Salvo M.L., Hunt S., Claude J.B. \& SCHIRCH V. 2006: Crystal structure of pyridoxal kinase from the Escherichia coli pdxk gene: Implications for the classification of pyridoxal kinases. J. Bacteriol. 188: $4542-4552$.

Sakurai T.H., OhKaw K. \& Matsuda M. 1993: Purification and properties of pyridoxal kinase from bovine brain. Mol. Cell Biochem. 119: 203-207.

ScotT T.C. \& Phillips M.A. 1997: Characterization of Trypanosome Brucei pyridoxal kinase: purification, gene isolation and expression in Escherichia coli. Mol. Biochem. Parasitol. 88: $1-11$.

Shi R.J., Zhang J.Y., Jiang C.J. \& Huang L.Q. 2007: Bombyx mori pyridoxal kinase cDNA cloning and enzymatic characterization. J. Genet. Genom. 34: 683-690.

Tang L., Li M.H., Cao P., Wang F., Chang W.R., Bach S., Reinhardt J., Ferandin Y., Galons H., Wan Y., Gray N., MeiJer L., JiAng T. \& Liang D.C. 2005: Crystal structure of pyridoxal kinase in complex with roscovitine and derivatives. J. Biol. Chem. 280: 31220-31229.

Wang H., Liu D., Liu C. \& Zhang A. 2004: The pyridoxal kinase gene, TaPdxk from wheat complements vitamin $\mathrm{B}_{6}$ synthesis-defective Escherichia coli. J. Plant Physiol. 161: 1053-1060.

White R.S. \& Dempsey W.B. 1970: Purification and properties of vitamin $\mathrm{B}_{6}$ kinase from Escherichia coli B. Biochemistry 9: 4057-4064.

Yang Y., Zhao G. \& WinkLer M.E. 1996: Identification of the pdxK gene that encodes pyridoxine (vitamin $\mathrm{B}_{6}$ ) kinase in Escherichia coli k-12. FEMS Microbiol. Lett. 141: 89-95.

Yang Y., Tsui H.C., Man T.K. \& WinkLer M.E. 1998: Identification and function of the pdxY gene, which encodes a novel pyridoxal kinase involved in the salvage pathway of pyridoxal 5'phosphate biosynthesis in Escherichia coli k-12. $J$. Bacteriol. 180: 1814-1821.

Zhang J.Y. \& Huang L.Q. 2003: Distribution, movement and metabolism of vitamin $\mathrm{B}_{6}$ compounds in the silkworm, Bombyx mori. Acta Entomol. Sin. 46: 277-281 [in Chinese with English abstr.].

Zhang Y., Dougherty M., Downs D.M. \& Ealick S.E. 2004: Crystal structure of an aminoimidazole riboside kinase from Salmonella enterica: implications for the evolution of the ribokinase superfamily. Structure 12: 1809-1821.

Received February 10, 2010; revised and accepted July 7, 2010 